\title{
In-the-Ear Circular-Shaped Balanced Inverted-A Antenna for Hearing Instruments
}

Kammersgaard, Nikolaj Peter Iversen; Kvist, Søren Helstrup; Thaysen, Jesper; Jakobsen, Kaj Bjarne

Published in:

I E E E Antennas and Wireless Propagation Letters

Link to article, DOI:

10.1109/LAWP.2016.2538966

Publication date:

2016

Document Version

Peer reviewed version

Link back to DTU Orbit

Citation (APA):

Kammersgaard, N. P. I., Kvist, S. H., Thaysen, J., \& Jakobsen, K. B. (2016). In-the-Ear Circular-Shaped

Balanced Inverted-A Antenna for Hearing Instruments. I E E E Antennas and Wireless Propagation Letters, 15, 1839 - 1843. https://doi.org/10.1109/LAWP.2016.2538966

\section{General rights}

Copyright and moral rights for the publications made accessible in the public portal are retained by the authors and/or other copyright owners and it is a condition of accessing publications that users recognise and abide by the legal requirements associated with these rights.

- Users may download and print one copy of any publication from the public portal for the purpose of private study or research.

- You may not further distribute the material or use it for any profit-making activity or commercial gain

- You may freely distribute the URL identifying the publication in the public portal 


\title{
In-the-Ear Circular-Shaped Balanced Inverted-A Antenna for Hearing Instruments
}

\author{
Nikolaj P. B. Kammersgaard, Søren H. Kvist, Jesper Thaysen, and Kaj B. Jakobsen
}

\begin{abstract}
A novel in-the-ear antenna for hearing instruments that operates at $2.45 \mathrm{GHz}$ is presented. The antenna is designed to obtain a polarization perpendicular to the surface of the head in order to optimize the ear-to-ear communication. The antenna consists of a bent dipole with a shorting pin used for impedance matching. It is self-resonant and well matched in the entire ISM band from $2.40 \mathrm{GHz}$ to $2.48 \mathrm{GHz}$. The simulated and measured peak ear-to-ear path gain $\left|S_{21}\right|$ is $-74.5 \mathbf{d B}$ and $-72.9 \mathbf{~ d B}$, respectively. The radiation pattern of the antenna is analyzed and the implications of the radiation pattern on the ear-to-ear communication are discussed.
\end{abstract}

Index Terms-Creeping waves, ear-to-ear, hearing instrument, in-the-ear, on-body, path gain, WBAN.

\section{INTRODUCTION}

Research and applications within on-body communication and Wireless Body Area Networks (WBAN) have increased significantly in the last decade. Numerous wireless wearable devices are now available. Within the hearing instrument (HI) industry, wireless connectivity is also in focus. There is an interest in enabling on-body communication between the HIs and wireless wearable devices such as smart phones. This makes it possible to control the HI settings from the phone and to use the HIs as a wireless headset. Off-body communication with for example TVs for sound streaming to the HIs is desired as well. Furthermore, wireless on-body ear-to-ear (E2E) communication between the HIs is desired in order to improve their capability to restore hearing.

The Industrial, Scientific, and Medical (ISM) band from $2.40 \mathrm{GHz}$ to $2.48 \mathrm{GHz}$ is especially interesting since it is a worldwide license-free band that enables communication with phones and other wireless devices through Bluetooth. Since it is desirable to have only one radio transceiver in a $\mathrm{HI}$, the ISM band is preferable for all wireless communication needs of the HI. In the ISM band, communication between a wireless off-body device or a wireless wearable device and the HIs is significantly easier to achieve than on-body E2E communication between the HIs. This is caused by the fact that such wireless devices are often physically larger than HIs, and therefore offer more efficient antennas and less strict requirements to power consumption. Also, the antennas in these devices do not experience the same near-field losses caused by the human body as antennas in HIs, which are almost

N. P. B. Kammersgaard and K. B. Jakobsen are with the Department of Electrical Engineering, Electromagnetic Systems, Technical University of Denmark, Ørsteds Plads, Building 348, DK-2800 Kgs. Lyngby, Denmark (email: npivka@elektro.dtu.dk)

N. P. B. Kammersgaard, S. H. Kvist and J. Thaysen are with GN ReSound A/S, Lautrupbjerg 7, DK-2750 Ballerup, Denmark

Manuscript received July 10, 2015.

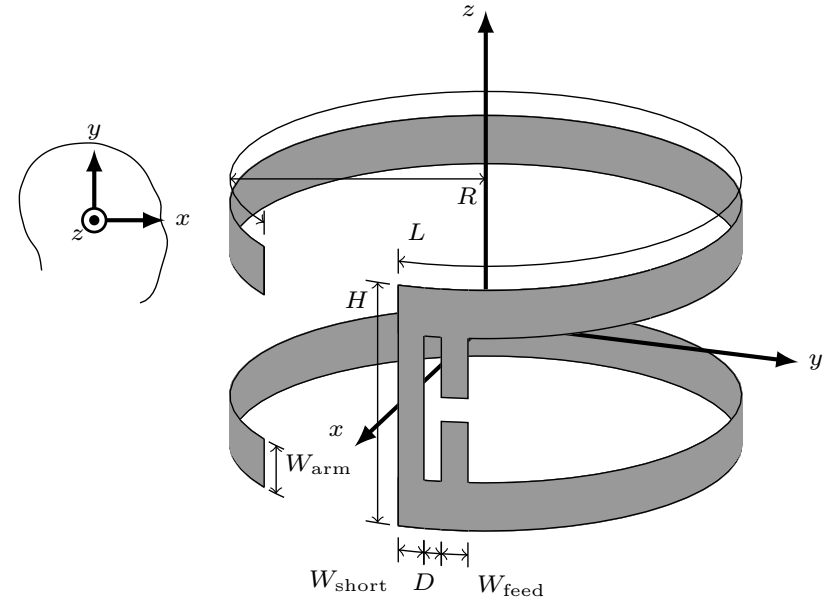

Fig. 1. The circular-shaped balanced inverted-A antenna.

completely surrounded by the human tissue. Furthermore, the propagation loss between the HIs alone is more than $40 \mathrm{~dB}$ [1]. Therefore, the main focus is to optimize the E2E path gain.

Most antenna research has been focused on behind-the-ear (BTE) HIs. In [2] an antenna for BTE HIs is presented with a path gain $\left|S_{21}\right|$ of $-52 \mathrm{~dB}$. This antenna concept has also been used for commercial products [3]. For cosmetic and acoustic reasons many HI users prefer in-the-ear (ITE) HIs instead of BTE HIs. Due to the higher loss from the human tissue experienced by an ITE antenna, the path gain is lower than for BTE antennas. In [4], [5] antennas for ITE HIs are presented. The best path gain obtained is $-89 \mathrm{~dB}$. In [6], [7] an antenna with a simulated and measured E2E path gain at $2.45 \mathrm{GHz}$ of $-85.9 \mathrm{~dB}$ and $-82.1 \mathrm{~dB}$, respectively, is presented. The antenna is polarized parallel to the head, which is not optimal for on-body communication. Here, a novel ITE antenna with perpendicular polarization with respect to the surface of the head and improved performance is presented.

In Section II the theory behind the antenna will be presented. In Section III the antenna simulation and measurement setup will be presented. In Section IV the results from the simulation and cabled measurements of a prototype will be presented and discussed. Finally, the conclusion is included in Section V.

\section{THEORY}

At $2.45 \mathrm{GHz}$ virtually no energy propagates through the body, since the body is very lossy [8]. It has been shown that 
TABLE I

OPTIMIZED ANTENNA DESIGN PARAMETERS

\begin{tabular}{lr}
\hline Parameter & $\begin{array}{r}\text { Value } \\
(\mathrm{mm})\end{array}$ \\
\hline \hline$L$ & 29 \\
$H$ & 5.0 \\
$W_{\text {arm }}$ & 1.0 \\
$W_{\text {short }}$ & 0.60 \\
$W_{\text {feed }}$ & 0.60 \\
$D$ & 0.30 \\
$R$ & 5.0 \\
\hline
\end{tabular}

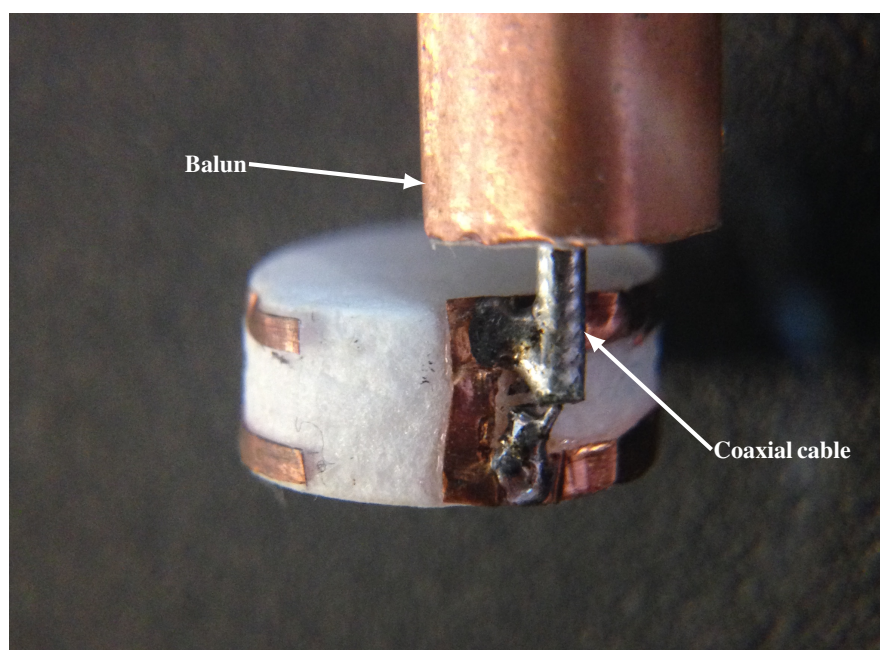

Fig. 2. The fabricated prototype of the circular-shaped balanced inverted-A antenna. The connected coaxial cable and balun are seen at the top.

the energy propagates around the body as creeping waves [9]. Furthermore, it has been shown that the E2E communication channel can be modeled as a number of elliptical paths around the head [10], [11]. In [11] an on-body radiation pattern is introduced and used to estimate the magnitude of the creeping wave launched in different directions. The on-body radiation pattern will be used to evaluate the radiation pattern of the antenna. In [11] only the magnitude is used. Here the phase of the electric field will be included together with the gain as expressed by Eq. 1:

$$
G_{\text {on-body }}(\phi)=\int_{0}^{\pi} G_{\theta}(\theta, \phi) e^{j \angle E_{\theta}(\theta, \phi)} \sin \theta d \theta
$$

where $G_{\theta}(\theta, \phi)$ is the $\theta$-component of the gain for the antenna mounted on the head, and $E_{\theta}(\theta, \phi)$ is the $\theta$-component of the electric field for the antenna when mounted on the head. The resulting $G_{\text {on-body }}(\phi)$ will thus have a magnitude or "gain" and a phase. It is noted that only the $\theta$-component is used since the $\phi$-component of the creeping wave decays much faster. In [12], [13] it is shown that a perpendicular polarization with respect to the surface of the head is preferable in order to obtain the highest possible path gain. Therefore, the antenna presented here has been designed to obtain perpendicular polarization.

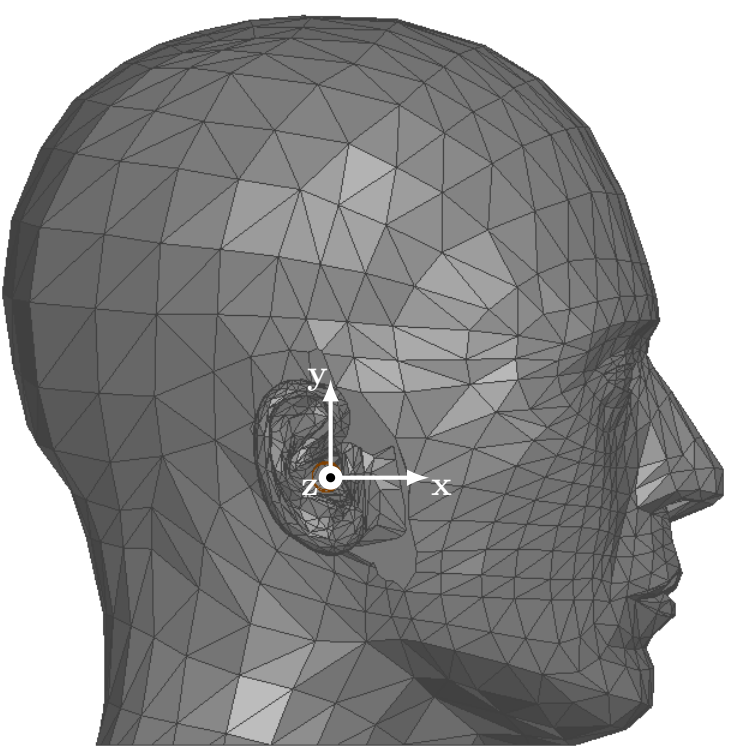

(a)

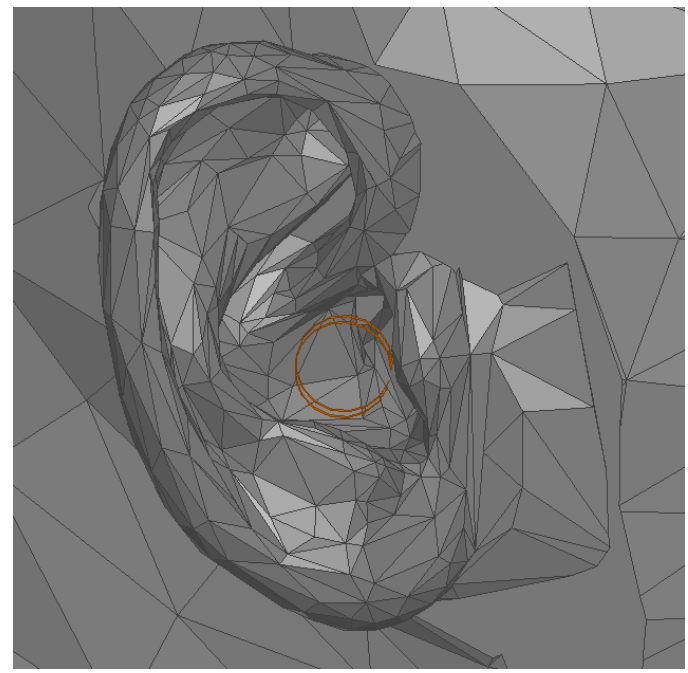

(b)

Fig. 3. The SAM phantom head (a) with the coordinate system used and a close up of the realistic ear (b) where the antenna can be seen (orange).

\section{EXPERIMENTAL SETUP}

The antenna used, an inverted-A antenna, consists of a bent dipole and a shorting pin as seen in Fig. 1. The dimensions of the antenna are given in Table I. A coordinate system is introduced where the $\mathrm{z}$-axis is perpendicular to the surface of the head, the xy-plane coincides with the surface of the head, and the $\mathrm{x}$-axis points towards the front of the head. The antenna is symmetric around the xy-plane. Since the antenna is only $5 \mathrm{~mm}$ tall, it is completely hidden by the tragus, i.e., the cartilaginous fleshy projection that partially covers the entrance to the external ear, when seen from the front of the head. The total length of the dipole is around a half wavelength at $2.45 \mathrm{GHz}$. This ensures that the antenna is selfresonant. The antenna has been bent to minimize the size. For half-wave dipole antennas the highest currents are around the feed. The feed is oriented perpendicular to the surface of the head. This ensures that the desired polarization is obtained. 
The currents on the two arms are opposite, and thus the electric field cancels in the far-field, which leaves only the radiation from the perpendicular current, as desired. The shorting pin has been introduced to match the antenna to $50 \Omega$. The distance between the shorting pin and the feed point of the antenna impedance was adjusted to obtain the desired impedance of $50 \Omega$.

Two prototypes of the antenna were fabricated. One of these can be seen in Fig. 2. The prototype was cut in copper tape (thickness $35 \mu \mathrm{m}$ and $\sigma=58 \mathrm{MS} / \mathrm{m}$ ) and was glued onto a dielectric cylinder made of ROHACELL ${ }^{\circledR} \mathrm{HF}\left(\epsilon_{\mathrm{r}}^{\prime}=1.05\right.$ and $\tan \delta<0.0002)$. The antenna was fed from a coaxial cable, which was fitted with a balun in order to reduce the parasitic currents on the cable. The prototypes were placed in the ear of a test person and the scattering parameters were measured with a vector network analyzer in a radio anechoic chamber. The antennas were carefully placed with the shorts pointed towards the front of the head to ensure that the coordinate systems of Fig. 1 and Fig. 3 align as in the simulation setup. This was done since variations were seen if the antennas were rotated. Furthermore, the antennas were placed in the center of the ear opening with equal distance to the surrounding skin to ensure consistent measurements. Four independent measurements on the test person were done, where the antennas were removed from the ear and placed again. The median measurement with respect to the path gain at $2.45 \mathrm{GHz}$ was used in the results, i.e. the measurement with the third highest path gain at $2.45 \mathrm{GHz}$. The mean of the four path gains at $2.45 \mathrm{GHz}$ was $-70.9 \mathrm{~dB}$ and the mean plus or minus the standard deviation was $-69.1 \mathrm{~dB}$ and $-74.2 \mathrm{~dB}$.

The simulations were done on the Specific Anthropomorphic Mannequin (SAM), which had been modified with realistic ears. The model can be seen in Fig. 3 with the antenna visible in the ear. The simulations were made in ANSYS HFSS 2014. For the simulations and measurements, a characteristic impedance $Z_{0}$ of $50 \Omega$ was used.

\section{REsults AND Discussion}

The simulated and measured path gain $\left|S_{21}\right|$ can be seen in Fig. 4. The simulated and measured peak E2E path gain is $-74.5 \mathrm{~dB}$ and $-72.9 \mathrm{~dB}$, respectively. Within the entire ISM band, the simulated and measured E2E path gain is better than $-77.8 \mathrm{~dB}$ and $-74.4 \mathrm{~dB}$, respectively. As seen in Table II this is more than $5 \mathrm{~dB}$ higher than any other path gains reported in the literature [4], [5], [6], [7]. The result is directly comparable to that of [6], [7] since the antenna is contained in the same cylinder and the same experimental setup is used. The main cause of the improved E2E path gain is attributed the polarization. It is noted that the radiation pattern of the antenna in free-space is the same as that of an infinitesimal dipole oriented in the $\mathrm{z}$-direction and therefore completely $\theta$-polarized. In the simulation where the antenna is placed inside the ear, the $\theta$ polarization is $7.1 \mathrm{~dB}$ stronger than the $\phi$ polarization. This shows that the antenna is polarized as intended. The polarization of [6], [7] is parallel to the surface of the head. This is believed to be the main course of the difference in performance between [6], [7] and this work. The

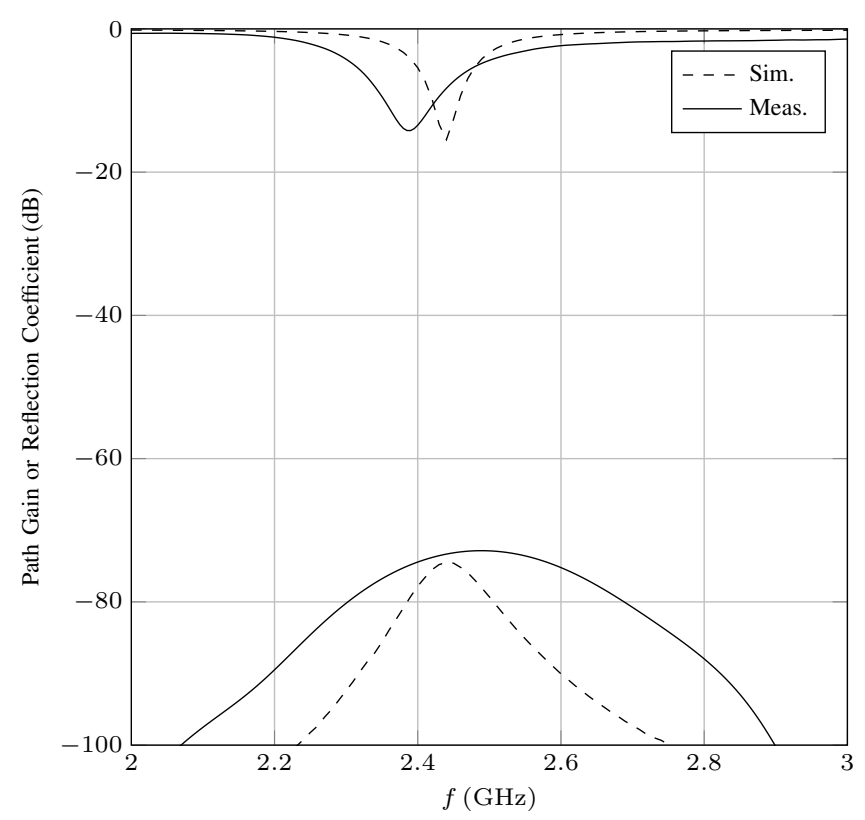

Fig. 4. Simulated (dashed line) and measured (circles) E2E path gain and reflection coefficient.

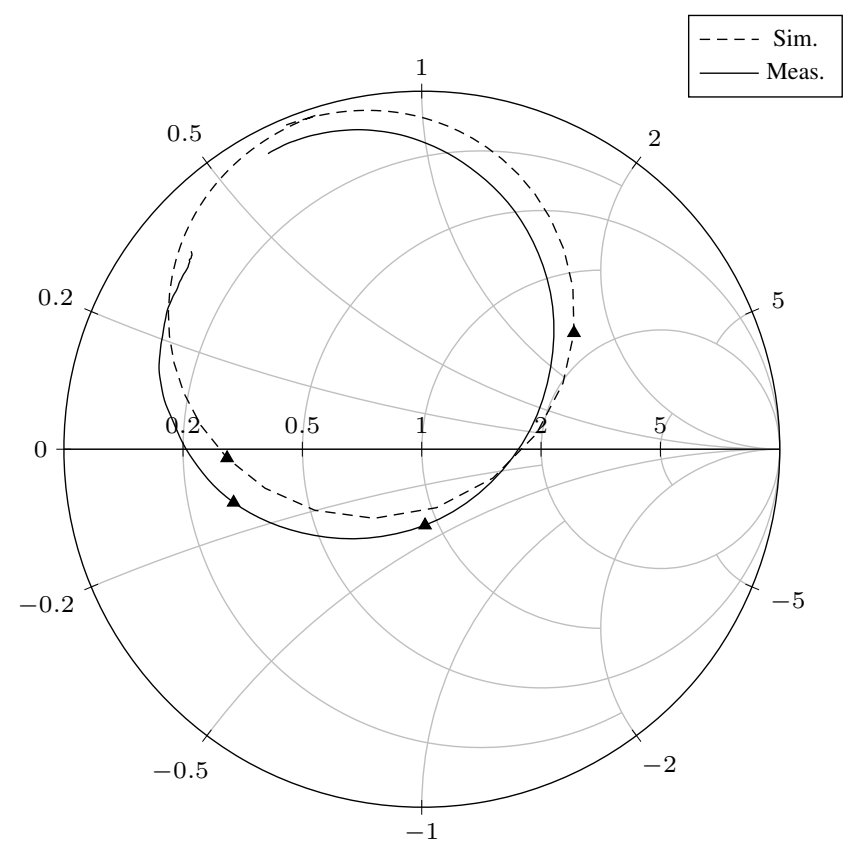

Fig. 5. Smith chart that shows the simulated (dashed line) and measured (solid line) reflection coefficient. The lower and upper frequency in the ISM band are marked by triangles.

simulated and measured reflection coefficient is shown on a logarithmic scale in Fig. 4 and in the Smith chart in Fig. 5. It is seen that the antenna is well matched in the entire ISM band. It is seen from the reflection coefficient and the path gain that the prototype is more broadband. This is due to higher loss in the measurements, and that the balun fitted on the prototype only works in the proximity of $2.45 \mathrm{GHz}$. The magnitude of the simulated on-body radiation pattern at 2.45 GHz calculated from Eq. 1 is seen in Fig. 6. From the radiation pattern it is seen that the antenna launches creeping 




Fig. 6. Magnitude of the simulated on-body radiation pattern at $2.45 \mathrm{GHz}$ (solid line). The dashed line shows the contour of the head.

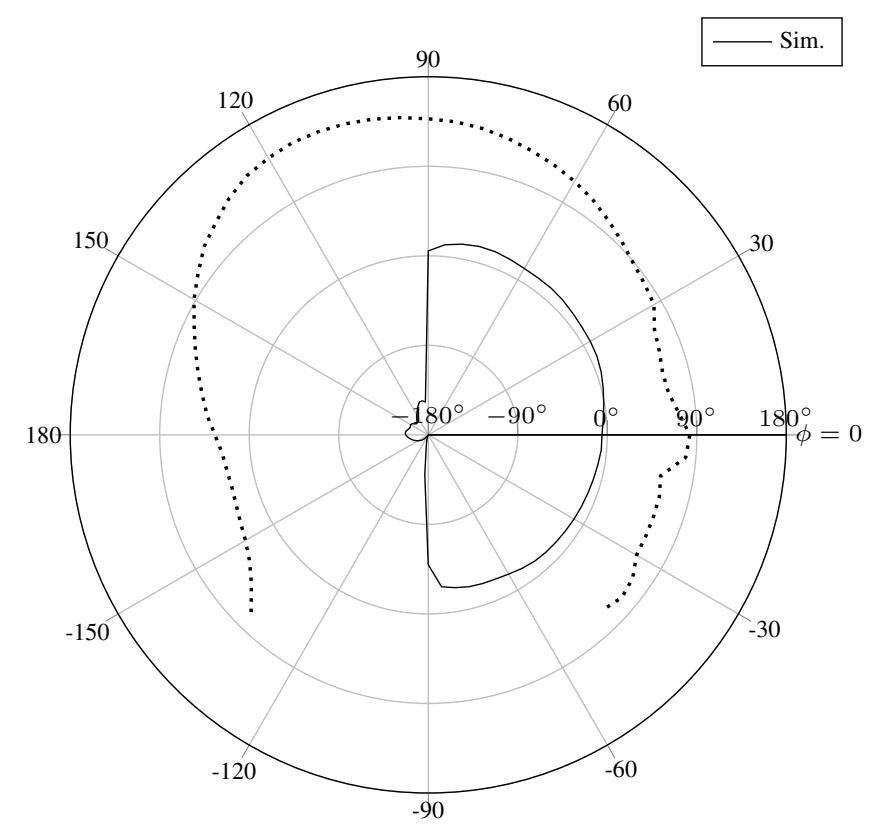

Fig. 7. Phase of the simulated on-body radiation pattern at $2.45 \mathrm{GHz}$ (solid line). The dashed line shows the contour of the head.

waves primarily towards the back and front of the head. The main wave is towards the front of the head. The phase of the simulated on-body radiation pattern at $2.45 \mathrm{GHz}$ is shown in Fig. 7. There is an electric phase difference between the forward and backward directions of around $155^{\circ}$, which shows that the antenna launches two separate waves. If the radiation pattern is compared to the one in [14], which is for a short dipole of length $4 \mathrm{~mm}$ placed in the ear, it is seen that they are almost completely alike. The radiation pattern in [14] is explained by the presence of the pinna, i.e., the outer ear. The gain pattern is also quite similar to that of the ITE
TABLE II

COMPARISON WITH PREVIOUSLY REPORTED E2E PATH GAINS.

\begin{tabular}{lr}
\hline Paper & E2E path gain at $2.45 \mathrm{GHz}$ \\
\hline \hline This work & $-74.6 \mathrm{~dB}$ \\
Chandra et al. [4] & $-91.7 \mathrm{~dB}$ \\
Huitema et al. [5] & $-89 \mathrm{~dB} /-95 \mathrm{~dB} *$ \\
Kammersgaard et al. [6], [7] & $-85.9 \mathrm{~dB}$ \\
\hline *Distance between antennas 160 mm / 150 mm.
\end{tabular}

antenna presented in [7], which indicates that the shape of the pattern is dominated by the pinna and not the antenna. If the radiation pattern is compared to the radiation pattern in Fig. 6 in [11], which is from a proposed BTE antenna, the following is observed. The ITE antenna has lower gain than the BTE antenna, which can be explained by the position inside the ear. Furthermore, the BTE antenna's main lobe is towards the back of the head, which is opposite for the ITE antenna. This can be explained by the fact that the pinna is blocking the creeping wave towards the front for the BTE antenna and towards the back for the ITE antenna.

\section{CONCLUSION}

A novel ITE circular-shaped balanced inverted-A antenna for HIs has been designed, simulated, fabricated, and measured. The antenna is self-resonant due to the near half wavelength total length. It is well matched to $50 \Omega$ in the ISM band due to the shorting pin. Furthermore, it is polarized perpendicular to the surface of the head in order to optimize the E2E path gain. The antenna yields a peak E2E path gain $\left|S_{21}\right|$ of $-74.5 \mathrm{~dB}$ and $-72.9 \mathrm{~dB}$ for the simulation and measurement, respectively. The path gain is significantly higher than previously published results. In the entire ISM band the E2E path gain $\left|S_{21}\right|$ is better than $-77.8 \mathrm{~dB}$ and $-74.4 \mathrm{~dB}$ for the simulation and measurement, respectively.

The on-body radiation pattern of the ITE antenna has been analyzed and compared to the radiation pattern of a BTE antenna. The ITE antenna has two lobes with the main one towards the front of the head, while the BTE antenna has its main lobe towards the back. This is caused by the pinna.

\section{REFERENCES}

[1] Alves, Thierry Emmanuel Pires and Poussot, Benoit and Laheurte and Jean-Marc, Analytical Propagation Modeling of BAN Channels Based on the Creeping-Wave Theory, in IEEE Trans. Antennas Propagat., vol. 59, no. 4, pp. 1269-1274, 2011.

[2] S. H. Kvist, S. Özden, J. Thaysen and K. B. Jakobsen, Improvement of the Ear-to-Ear Path Gain at $2.45 \mathrm{GHz}$ Using Parasitic Antenna Element, 6th European Conference on Antennas and Propagation (EuCAP), pp. 944-947, 2012.

[3] GN ReSound A/S, ReSound Verso, August 2014, http://www.resound com/products/hearing-aids/resound-verso

[4] R. Chandra and A. J. Johansson, Miniaturized antennas for link between binaural hearing aids, in Proc. 32nd Annu. Int. Conf. of the IEEE Eng. in Med. and Biol. Soc., EMBC, pp. 688-691, Aug. 2010.

[5] L. Huitema, S. Sufyar, C. Delaveaud and R. D'Errico, Miniature Antenna Effect on the Ear-to-Ear Radio Channel Characteristics, 6th European Conference on Antennas and Propagation, pp. 3402-3406, 2012.

[6] N. P. I. Kammersgaard, S. H. Kvist, J. Thaysen and K. B. Jakobsen, In-the-ear spiral monopole antenna for hearing instruments, in IET Electronics Letters, vol. 50, no. 21, pp. 1509-1510, 2014. 
[7] N. P. I. Kammersgaard, S. H. Kvist, J. Thaysen and K. B. Jakobsen, Body-Worn Spiral Monopole Antenna for Body-Centric Communications, in 2015 International Workshop on Antenna Technology (iWAT), Seoul, Republic of Korea, March. 2015.

[8] S. Gabriel, R. W. Lau, and C. Gabriel, The dielectric properties of biological tissues: III. Parametric models for the dielectric spectrum of tissues. Physics in medicine and biology, vol. 41, pp. 2271?2293, 1996.

[9] J. Ryckaert, P. De Doncker, R. Meys, A. de Le Hoye, and S. Donnay, Channel Model for Wireless Communication Around Human Body, Electronics Letters, vol. 40, no. 9, pp. 543-544, Apr. 2004.

[10] R. Chandra and A. J. Johansson, A Link Loss Model for the OnBody Propagation Channel for Binaural Hearing Aids, in IEEE Trans. Antennas Propagat., vol. 61, no. 12, pp. 6180-6190, Dec. 2013.

[11] S. H. Kvist, J. Thaysen and K. B. Jakobsen, Ear-to-Ear On-Body
Channel Model for Hearing Aid Applications, in IEEE Trans. Antennas Propagat., vol. 63, no. 1, pp. 344-352, 2015.

[12] P. S. Hall, Y. Hao, Y. I. Nechayev, et al., Antennas and Propagation for On-Body Communication Systems, IEEE Antennas Propag. Mag., vol. 49, no. 3, pp. 41-58, 2007.

[13] S. H. Kvist, J. Thaysen and K. B. Jakobsen, Polarization of Unbalanced Antennas for Ear-to-Ear On-Body Communications at $2.45 \mathrm{GHz}$, in 2011 Loughborough Antennas and Propagation Conference (LAPC), Loughborough, UK, Oct. 2011.

[14] N. P. I. Kammersgaard, S. H. Kvist, J. Thaysen and K. B. Jakobsen, Pinna Model for Hearing Instrument Applications, in 2014 Loughborough Antennas and Propagation Conference (LAPC), Loughborough, UK, Nov. 2014. 